\title{
Ovarian responses to lactation management strategies
}

\author{
N.M. Soede ${ }^{1}$, W. Hazeleger ${ }^{1}$, R. Gerritsen ${ }^{2}$, P. Langendijk ${ }^{3}$ \\ and B. Kemp ${ }^{1}$
}

'Adaptation Physiology Group, PO Box 3386700 AH Wageningen University, Wageningen, The Netherlands; ${ }^{2}$ Current address: Schothorst Feed Research, Lelystad; ${ }^{3}$ SARDI Livestock, Roseworthy

Campus, South Australia

\begin{abstract}
A number of lactation management strategies can be applied to reduce negative effects of lactation on post-weaning fertility. This paper focuses on effects of lactation length, Intermittent Suckling and Split Weaning on follicle development and subsequent oestrus. It is concluded that a lactation length of less than 3 weeks still leads to suboptimal reproductive performance in our modern sows. Further, both Intermittent Suckling and Split Weaning stimulate lactational follicle development and oestrus, but the variation in response between sows still limits practical application.
\end{abstract}

\section{Introduction}

During lactation, both the suckling intensity of the piglets and the negative energy and/or protein balance of the sows normally inhibit the growth of pre-ovulatory follicles and therefore, prevents the occurrence of lactational oestrus. Gonadotrophin release and thus follicle development can besuppressed to such an extent that post-weaning follicle development and subsequent fertility (weaning-to-oestrus interval, ovulation rate, embryo survival and subsequent farrowing rate and litter size) are negatively influenced too. This is most obvious in first litter sows, but is also observed in older parity sows with extensive lactational weight loss (Thaker \& Bilkei 2005). A number of lactation management strategies can be applied to reduce negative effects of lactation on post-weaning fertility: optimizing lactation length, Intermittent Suckling (i.e. temporary separation of sows and piglets during the last days of lactation) and Split Weaning (i.e. a reduction of litter size during the last days of lactation). Before reviewing these strategies, a short overview is given of the mechanisms leading to lactational suppression of follicle development.

\section{Lactational suppression of follicle development}

This paper briefly describes the most important factors that affect follicle development during lactation, as Quesnel (2009) in this volume focuses on lactational and nutritional influences on follicle development.

Antral follicle development depends on the gonadotrophins $\mathrm{LH}$ and FSH. During established lactation, $\mathrm{LH}$-levels and pulsatile $\mathrm{LH}$ release are suppressed due to the suckling-induced inhibition of the GnRH-pulse generator (De Rensis et al. 1993). The level of LH-suppression is related to the suckling intensity, but also to the negative energy balance of the sows; in 
primiparous sows on a low feeding level, LH-levels were reduced compared to sows on a a high feeding level (e.g. (Quesnel \& Prunier 1998; Van Den Brand et al. 2000). Effects of lactation on FSH are less consistent, and seem more dependent on ovarian negative feedback (inhibin) than on suckling (reviewed by (Prunier et al. 2003).

In the course of lactation, LH-pulsatility normally restores (e.g. Van Den Brand et al. 2000), which may be related to a decrease in suckling frequency and intensity or to the increase in pituitary LH response to GnRH (e.g. Bevers et al. 1981; Rojanasthien et al. 1987). Concomitantly with the increase in LH-pulsatility, follicle size increases in the course of lactation. Thus, with progressing lactation, the follicle pool on the ovaries achieve a greater diameter, but most sows do not develop follicles beyond 3-4 mm until after weaning (Lucy et al. 2001), although occasionally sows develop pre-ovulatory follicles $(\sim 8 \mathrm{~mm})$ and ovulate during lactation.

The inhibition of $\mathrm{LH}$ release during lactation influences both lactational follicle development and the resumption of ovarian activity after weaning (Shaw \& Foxcroft 1985, Quesnel et al. 1998). Additionally, the positive feedback mechanism to oestradiol matures in the course of lactation, increasing the ability of sows to mount a pre-ovulatory LH-surge of sufficient magnitude (Sesti \& Britt 1993). These mechanisms together form the basis for lactational effects on subsequent fertility parameters, such as: weaning-to-oestrus interval, ovulation rate and even embryo surviva! (reviewed by Prunier et al. 2003), eventually affecting farrowing rate and litter size.

\section{Lactation management strategies}

To counteract negative consequences of lactation on subsequent fertility, several management strategies can be applied. These strategies aim to improve the energy balance of the sows and reduce the intensity of suckling in the last part of lactation either by reducing litter size (Split Weaning) or by limiting the period of suckling (Intermittent Suckling). Since lactation length in itself is a major determinant of post-weaning ovarian activity, it is discussed first.

\section{Lactation Length}

In 1982, Varley reviewed effects of day of weaning on subsequent reproductive functioning. He concluded that the weaning-to-oestrus interval was around 7 days when sows were weaned at 3 weeks or beyond, but increased when sows were weaned at less than 3 weeks of lactation. Further, lactation length did not seem to influence ovulation rate or fertilization rate, but embryo mortality around the time of implantation seemed to increase in sows with lactation lengths shorter than 24 days. As a result, subsequent litter size was reduced substantially. The negative consequences of short lactation lengths on litter size were attributed to the compromised uterine development after weaning.

Since the review by Varley (1982), sows have changed substantially. Due to genetic selection, current sows have a higher percentage of lean muscle tissue, a lower level of backfat and improved reproductive performance as shown by the lower percentage of sows with delayed weaning-to-oestrus intervals and increased litter size. So, how does lactation length affect reproductive functioning in modern sows?

Hardly any studies have investigated immediate post-weaning reproductive physiology of sows in relation to lactation length. An interesting exception is the study by (Willis et al. 2003) who compared sows weaned at Day 14 with sows weaned at Day 24 of lactation. They found a lower LH-pulsatility pre- and post-weaning, consistent with an HPO that is not fully recovered at Day 14 of lactation. They also found higher FSH levels and a delayed increase in post-weaning oestrogen levels with weaning at Day 14 , consistent with a suppressed follicular development at Day 14. 
How does suppressed follicle development at weaning affect further reproductive functioning? A few studies have analysed farm data on sow performance in relation to lactation length. These studies show that the weaning-to-service interval is consistently short when lactation length is beyond 21 days, but weaning-to-service interval increases after shorter lactation lengths (see Fig. 1). In sows with short lactations that did not show oestrus by day 6 after weaning, Knox \& Rodriguez Zas (2001) consistently found smaller follicles at weaning and at 3 days after weaning, suggesting a suppressed follicle development in these sows.

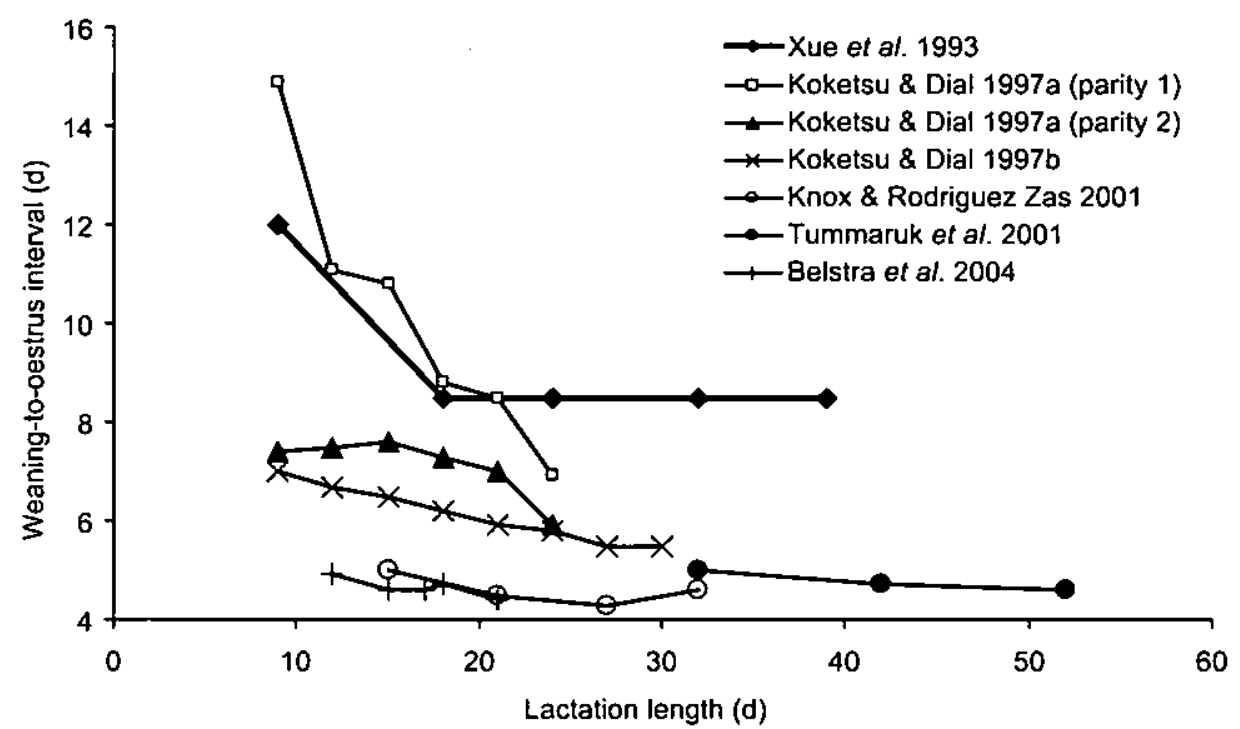

Fig. 1 Effect of lactation length on weaning-to-oestrus interval NB Knox and Rodriguez Zas (2001): only sows showing oestrus within 8 days from weaning. The percentage of sows showing oestrus within 8 days was $35 \%, 94 \%, 98 \%$ and $96 \%$, for the shortest to longest lactation length classes; Tummaruk et al., (2001): sows with oestrus within 20 days $[90.3 \%$; percentages not shown per lactation length class]; Belstra et al., (2004): only sows showing oestrus within 10 days from weaning. The percentage of sows showing oestrus within 10 days was $92 \%, 92 \%, 90 \%, 94 \%$ and $98 \%$ for the shortest to longest lactation length classes.

Also when oestrus is not delayed, reproductive processes may still be affected. For example, Knox \& Rodriguez Zas (2001) found that in sows with short lactation $(<16 d)$, the percentage of sows showing oestrus was reduced $(35 \%)$, and also the percentage of these sows that ovulated $(78 \%)$ compared to sows with a longer lactation length (e.g. for sows with a lactation length of $25-31 \mathrm{~d}$ : $98 \%$ showed oestrus, of which $98 \%$ ovulated). The sows that failed to ovulate either showed a short/intermittent oestrus with only small or medium sized follicles or ovarian cysts at that time or had a long oestrus period with normal sized pre-ovulatory follicles that did not ovulate within the first 5 days of oestrus. In ovulating sows, lactation length did not affect follicle size at ovulation. Thus, even when oestrogen production of sows with short lactations is sufficient for oestrous behaviour, the immaturity of the positive feedback system may prevent/ disable the occurrence of an LH-surge (Sesti \& Britt 1993), and consequently, these sows fail to ovulate. If the LH surge fails in sows with normal sized pre-ovulatory follicles, follicles may become cystic. There are no recent reports outlining the influence of lactation length on the development of cystic follicles or cystic ovaries; Svajgr et al. (1974) found that the number of cystic follicles doubled for sows with a lactation length of $13 \mathrm{~d}$ compared to $24 \mathrm{~d}$ ( $1.3 \mathrm{vs} 0.6$ ). Consistent with the earlier review by Varley (1982), Willis et al. (2003) did not find effects of lactation length on ovulation rate. 
A possible disadvantage of longer lactations for farm reproductive parameters can be the increase in the number of sows with lactational ovulation. This may especially occur in multiparous sows from specific prolific breeds, but may occur in any sow with a low number of suckling piglets or a high feed intake during lactation. Lactational ovulation is often not noted and, such sows will thus be marked as 'delayed oestrus'.

Lactation length may also affect subsequent farrowing rate and litter size, as reviewed by Varley (1982). Also in more recent literature, short lactations (less than 3 weeks) negatively affect subsequent litter size and farrowing rate (e.g. Koketsu et al. 1997, Le Cozier et al. 1997). Further, the limited information that is available on reproductive performance for long lactations seems to indicate a positive influence of lactation lengths above $4 \mathrm{wks}$, both for farrowing rate $(+3 \%)$ and litter size (+0.6 piglets) (Gaustad-Aas et al. 2004), although such effects are not always found (Tummaruk et al. 2001) and may not result in a higher number of piglets per sow per year (Xue et al. 1993).

Summarising, especially short lactation lengths $(<3 \mathrm{wks})$ have a clear negative effect on post-weaning follicular development and subsequent interval to oestrus, ovulation response and even farrowing rate and litter size. These effects are related to the level at which lactation has suppressed follicle development. Effects of short lactation lengths on weaning-to-oestrus interval seem less evident in recent literature (see Fig. 1), although the true effect is masked by the relatively short cut-off points (e.g. oestrus up to 8 days from weaning (Knox \& Rodriguez Zas 2001) and oestrus up to 10 days from weaning (Belstra et al. 2004). Nevertheless, such reduced effects of short lactation lengths on weaning-to-oestrus interval may be related with the ongoing selection for short weaning-to-oestrus intervals. However, if this means ovulation of less developed follicles and oocytes, such sows may still have lower subsequent performance.

\section{Intermittent Suckling}

One way to reduce the suckling stimulus of the piglets and as such stimulate follicular development and subsequently lactational ovulation, is by introducing daily periods of separation of sows and piglets during the last part of lactation. This procedure is termed reduced or limited suckling, interrupted suckling, or Intermittent Suckling (IS). Recently, Langendijk et al. (2006) and Gerritsen et al. (2008b) reviewed effects of Intermittent Suckling on subsequent fertility. They showed that the enormous variation in (lactational) oestrous response of sows in the different Intermittent Suckling regimes can be attributed to the regimes used, but also to differences between sows. In short, up to $90 \%$ of sows may show lactational oestrus if the Intermittent Suckling does not start too early in lactation (preferably later than Day 18) and lasts for at least $10 \mathrm{~h}$ per day. During separation, sows should be housed out of sight and hearing from the piglets, preferably allowing some boar contact. The genotype of the sow is of major importance and also the parity, since primiparous sows have a lower oestrous response.

Interestingly, sows that respond to the treatment with oestrus do so in a synchronous fashion at a seemingly normal interval of 4 to 5 days from start of treatment (see Gerritsen et al. 2008b). Extending the duration of the treatment period does not seem to influence the oestrous response. As a consequence, a treatment period of $14 \mathrm{~d}$ compared to $7 \mathrm{~d}$ (Soede et al. 2009) did not significantly increase the oestrous response. Interestingly, in that study, the sows that did not show a lactational oestrus within the period that they were subjected to IS, showed a 'normal' weaning-to-oestrus interval once they were weaned. Thus, the oestrous response of sows in an Intermittent Suckling regime seems to be an 'all or none' phenomenon; either a 'normal' duration of the follicular phase, or no response, as was also concluded by Stevenson \& Davis (1984). 
Even though a considerable number of sows may show lactational oestrus in an Intermittent Suckling regime, other sows show varying patterns of response in terms of follicle development. In the experiments of Gerritsen et al. (2009); Gerritsen et al. (2008a) and Langendijk et al. (2009), ultrasound was performed daily to check the ovarian response to the Intermittent Suckling regimes. The following follicle development patterns could be distinguished; sows showing follicular growth with follicle diameters not reaching pre-ovulatory size $(<6 \mathrm{~mm})$ and sows developing follicles of pre-ovulatory size $(>6 \mathrm{~mm})$. Within the second category, follicles either ovulated, regressed or became cystic ( $>10 \mathrm{~mm}$, not ovulating). Fig. 2 shows the patterns of follicle development for each of these categories. Table 1 shows the number of sows for each of these ovarian response for weaned control sows (Day 21 of lactation) and for sows in which intermittent Suckling started at Day 14 or at Day 21 of lactation. Failure of sows to develop follicles beyond $6 \mathrm{~mm}$ was particularly observed when IS commenced early in lactation ( $13 \%$ for $\mathrm{D} 14$ vs $0 \%$ for $\mathrm{d} 21$ ), illustrating the recovery of gonadotropic secretory capacity during this period of lactation. Sows with follicular development beyond $6 \mathrm{~mm}$, mostly ovulated and showed oestrus. However, in some sows follicles regressed without ovulation (Table 1). This phenomenon (pre-ovulatory sized follicles regressing) has, to our knowledge not been described before and has not been observed before by our research group. FSH and LH release on the first day of IS did not seem limiting for normal follicle development in these sows (Langendijk et al. 2009). Nevertheless, the follicles in these sows were anoestrogenic (no increase in peripheral oestradiol levels) despite an increase in follicle diameter. In sows ovulating normally, an increased concentration of oestradiol was observed from day 2 of IS. We suggest that the follicles that regressed were not fully responsive to the increased FSH and $\mathrm{LH}$ secretion after commencement of IS. Some sows that showed pre-ovulatory follicle development $(>6 \mathrm{~mm}$ ) developed cystic follicles. Particularly sows that commenced IS at $14 \mathrm{~d}$ of lactation were prone to show this deviation in the follicular phase: in $13 \%$ of all D14 sows subjected to IS (vs 0\% for D21) all follicles turned cystic, or some follicles became cystic with the other follicles luteinising and forming corpora lutea. The sows with all follicles turning cystic had a normal follicular phase oestrogen rise, but had a very low or no LH surge and (consequently) no signs of luteinisation (no drop in oestradiol, no rise in progesterone), see Gerritsen et al. (2008b).

Table 1. Follicle development', ovulation and oestrus response [between brackets] in Intermittent Suckling regimes with $12 \mathrm{~h}$ daily separation starting at day 14 (IS14) or day 21 of lactation (IS21)

\begin{tabular}{|c|c|c|c|}
\hline & \multicolumn{3}{|c|}{ Treatment } \\
\hline & Control $^{3}$ & IS14 & IS21 \\
\hline & $N-36$ & $N-79$ & $N=23$ \\
\hline Follicular development remained $<6 \mathrm{~mm}$ & $\begin{array}{c}0 \% \\
{[0 \%]}\end{array}$ & $\begin{array}{l}13 \% \\
{[0 \%]}\end{array}$ & $\begin{array}{c}0 \% \\
{[0 \%]}\end{array}$ \\
\hline \multicolumn{4}{|l|}{ Follicular development reached $>6 \mathrm{~mm}$} \\
\hline Ovulation within 8d after start IS/wean & $\begin{array}{c}94 \% \text { d } \\
{[100 \%]}\end{array}$ & $\begin{array}{l}66 \% \\
{[90 \%]}\end{array}$ & $\begin{array}{l}87 \% \text { b } \\
{[95 \%]}\end{array}$ \\
\hline \multicolumn{4}{|l|}{ No ovulation } \\
\hline Regression of fọllicles & $\begin{array}{c}0 \\
{[0 \%]}\end{array}$ & $\begin{array}{c}9 \% \\
{[0 \%]}\end{array}$ & $\begin{array}{c}13 \% \\
{[100 \%]}\end{array}$ \\
\hline Cystic follicles & $\begin{array}{c}6 \% \text { l } \\
100 \%)\end{array}$ & $\begin{array}{c}13 \% \\
{[80 \%]}\end{array}$ & 0 \\
\hline
\end{tabular}

'Daily ultrasound from onset of IS or from weaning onwards

${ }^{2}$ Results are based on (Gerritsen et al. 2009; Gerritsen et al. 2008a; Langendijk et al. 2009);

${ }^{3}$ Control sows weaned at Day 21 of lactation

db $\mathrm{P}<0.05$ 


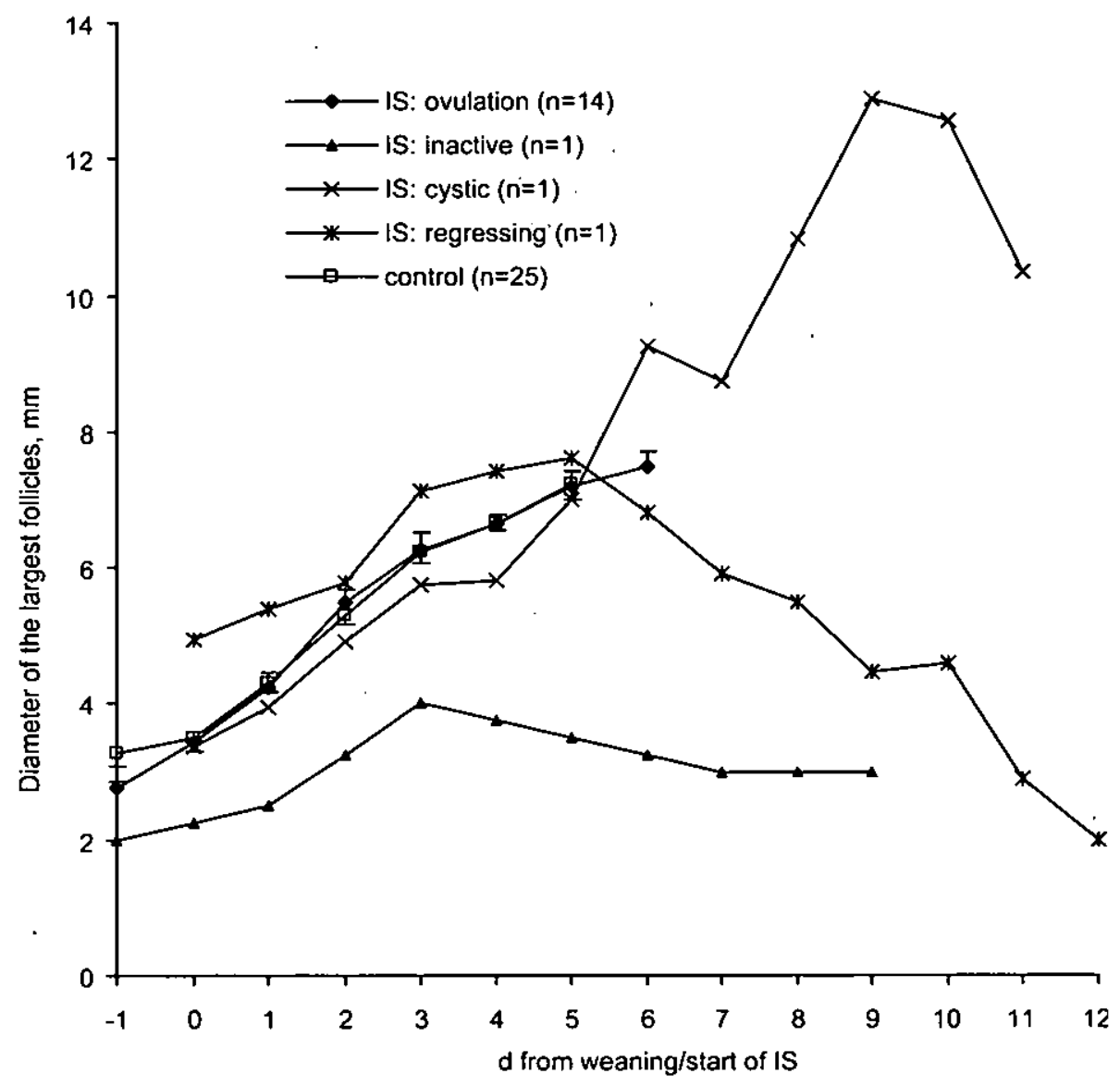

Fig. 2 Different patterns of follicle development in sows during the last day of full lactation (full lact) and after subsequent weaning (Control) or onset of Intermittent Suckling (IS). In IS, the majority of sows the follicles reached ovulatory size $(>6 \mathrm{~mm})$ and subsequently ovulated (IS:ovulation), but in others follicles never reached ovulatory size (IS:inactive, one example sow shown) or did reach ovulatory size and either developed cystic ovaries (IS:cystic, one example shown) or follicles regressed (IS: regressing, one example shown). [Langendijk, unpublished results].

This again illustrates that during early lactation, the postive feedback of oestradiol on the $\mathrm{LH}$ surge centre is still developing or there is insufficient $\mathrm{LH}$ to induce an adequate $\mathrm{LH}$ surge.

In the early studies on Intermittent Suckling, the majority of sows ovulated after weaning. Thus, from those studies it remains unclear if and how Intermittent Suckling and/or lactational inseminations affect pregnancy. Recent Intermittent Suckling studies (reviewed by Gerritsen et al. 2008b), suggest that pregnancy rate, embryo survival rate and embryo development are negatively affected if IS-induced ovulation takes places around Day 19-21 after farrowing (IS started at Day14) and IS continues after ovulation, which may be related with lower progesterone levels in these sows. When sows are inseminated more than 3 weeks after farrowing, neither litter size, nor farrowing rate are negatively affected by lactational inseminations in an IS-regime (Soede et al. 2009) or during 'normal' lactation (Gaustad-Aas et al. 2004). 
Summarizing, recent studies with Intermittent Suckling show that there is a large variation in oestrous response, in which specifically the onset of treatment, the genotype of the sows and parity of the sows is important. The oestrous response is an 'all or none' phenomenon, which means that sows either show oestrus after a follicular phase of normal duration or do not respond at all and show a normal return to oestrus after weaning. The majority of sows that show oestrus, normally ovulate with a normal ovulation rate, even though in some sows follicles may become cystic. When sows ovulate during an intermittent regime, they have a similar chance of becoming pregnant and remaining pregnant and a similar litter size compared to sows that are inseminated post weaning, but the negative effects of short farrow-to-insemination intervals also hold for Intermittent Suckling.

\section{Split weaning}

With Split Weaning, the suckling stimulus of the piglets is reduced and the energy balance of the sows is improved by the permanent removal of a part of the litter a few days before complete weaning. In the different studies reported, there was a considerable variation in the Split Weaning regimes; Split Weaning lasted for 3 to 7 days before complete weaning, leaving 2 to 6 piglets for the remaining lactation which lasted 17 to $35 \mathrm{~d}$. Matte et al. (1992) reviewed the reproductive performance of split wean sows and concluded that the reduction in the interval from weaning to oestrus was mostly affected by the number of piglets that remained with the sow during the last days of lactation. The largest reduction in weaning-to-oestrus interval was seen when only 3 piglets remained with the sow for 4.7 days. Interestingly, Grant (in: Varley \& Foxcroft 1990) showed that effects of Split Weaning (leaving 5 piglets with the sow) on both $\mathrm{LH}$ levels and follicle development after 7 days of treatment were larger when the 6 anterior teats had been covered compared to when only Split Weaning was applied. Since piglets had a similar growth rate in both treatments, and thus the metabolic demands on the sows were similar, it appears that effects on $\mathrm{LH}$ and follicle development are primarily mediated by the neural stimulation of suckling. Only few experiments have since evaluated effects of Split Weaning on reproductive physiology or performance of sows and these later experiments have all focused on the lower parity sows (Mahan 1993; Vesseur et al. 1997; Zak et al. 2008; Foxcroft et al. unpublished results). These studies also consistently show that the weaning to oestrus/insemination interval is reduced when Split Weaning is applied. Two recent studies have evaluated the role of the gonadotrophins in this effect. Degenstein et al. (2006) showed that during the whole period of Split Weaning (day 16-19), prolactin levels were reduced and FSH levels were increased. Further, Zak et al. (2008) found an acute increase in LH levels and $\mathrm{LH}$ pulse frequency in the $10 \mathrm{~h}$ following Split Weaning at day 18 . At the day of weaning ( $3 \mathrm{~d}$ later), average $\mathrm{LH}$ levels were similar to the control animals, both before and after final weaning. The day after weaning, split wean sows had more follicles with a diameter larger than $3 \mathrm{~mm}$. Thus, the increased LH levels, the higher FSH levels during the split-wean regime and possibly the lower prolactin levels together stimulate follicle development and shorten weaning-to-oestrus intervals.

As far as we know, hardly any information is available on the quality of ovulation in split weaned sows. However, the reproductive characteristics that have been measured show a slightly increased ovulation rate (17.7 compared to 15.5 (Zak et al. 2008)), a similar embryo survival rate at day $28(64 \%$ versus $60 \%$ (Zak et al. 2008)); similar subsequent litter size (Vesseur et al. 1997), and increased farrowing rate in parity 2 sows ( $97 \%$ versus $86 \%$ (Vesseur et al. 1997)). 
Thus, removing the majority of the litter for the last 3-5 days of lactation consistently shortens the weaning-to-oestrus intervals through a stimulation of follicular development, primarily by a reduction in suckling stimuli. The improvement in weaning-to-oestrus intervals is only seen in groups of sows with an otherwise extended weaning-to-oestrus interval. Further, the few papers that have investigated Split Weaning effects beyond oestrus are not very conclusive. Therefore effects on subsequent fertility remain unclear.

Table 2. Oestrus response in recent Split Weaning studies

\begin{tabular}{ccccccl}
\hline $\begin{array}{c}\text { Split wean } \\
\text { (d before } \\
\text { weaning) }\end{array}$ & $\begin{array}{c}\text { Litter size } \\
\text { before split- } \\
\text { wean }\end{array}$ & $\begin{array}{c}\text { Remaining } \\
\text { piglets }\end{array}$ & $\begin{array}{c}\text { Lactation } \\
\text { length (d) }\end{array}$ & Parity & $\begin{array}{c}\text { WOI' (d) } \\
\text { (compared to } \\
\text { Controls) }\end{array}$ & Source \\
\hline 7 & 9.8 & 4 & 30 & $1+3$ & $3.1(\mathrm{C}: 6.6)^{2}$ & (Mahan 1993) \\
7 & 10.3 & 6 & 28 & 1 & $5.6(\mathrm{C}: 5.9)^{3}$ & (Vesseur et al. 1997) \\
7 & 10.5 & 6 & 28 & 2 & $4.6^{*}$ (C: 5.4$)^{4}$ & (Vesseur et al. 1997) \\
3 & 9.6 & 4 (lightest) & 21 & 1 & $4.6^{*}$ (C: 5.7) & (Zak et al. 2008) \\
3 & $\mathrm{NM}$ & 5 (lightest) & 19 & $1+2$ & $4.9(\mathrm{C}: 5.2)$ & Foxcroft et al. (unpublished) \\
\hline
\end{tabular}

- $\mathrm{P}<0.05, \mathrm{NM}$ not mentioned

' WOI - Weaning-to-Oestrus interval

${ }^{2}$ Control sows were weaned at Day 23

${ }^{3}$ of sows that showed oestrus within $15 \mathrm{~d}$ after weaning $(52 \%$ and $58 \%$ )

* of sows that showed oestrus within $15 \mathrm{~d}$ after weaning $(62 \%$ and $63 \%$ )

\section{Concluding remarks}

As shown above, lactation management strategies such as Intermittent Suckling and Split Weaning may stimulate lactational follicle development and thereby postweaning oestrus onset by the combined effects of a reduced suckling intensity (most important) and improved energy balance of the sow. However, the benefits seem rather marginal in our modern sows that have been selected for short weaning-to-oestrus intervals and still not all sows will respond to the treatment. Concerning effects of lactation length, also for our modern sows, a 3-week lactation still seems to be required for optimal post-wean performance.

Besides applying optimal lactation management strategies, negative consequences of lactation on post-weaning fertility can also partly be counterbalanced by optimizing post-wean management, e.g. by boar stimulation and nutritional management. However, since the postweaning follicular period is normally very short, even optimal post-wean conditions may not be sufficient to optimize post-lactional fertility. Another possibility would be to allow sows to recover from lactation by postponing post-wean oestrus and insemination e.g. by short term use of a progesterone analogue.

\section{References}

Belstra BA, Flowers WL \& See MT 2004 Factors affecting temporal relationships between estrus and ovulation in commercial farms Animal Reproduction Science $84377-394$

Bevers MM, Willemse AH, Kruip TAM \& Van de Wiel DFM 1981 Prolactin levels and the L.H-response to synthetic LH-RH in the lactating sow. Animal Reproduction Science 4 155-163.
De Rensis F, Cosgrove JR \& Foxcroft GR 1993 Luteinizing hormone and prolactin responses to naloxone vary with stage of lactation in the sow. Biology of Reproduction 48 970-976.

Degenstein K, Wellen A, Zimmerman P, Shostak S, Patterson J, Dyck M \& Foxcroft GR 2006 Effect of split weaning on hormone release in lactating sows. Advances in Pork Production 17: Abstract no. 17. 
Gaustad-Aas AH, Hofmo PO \& Karlberg K 2004 The importance of farrowing to service interval in sows served during lactation or after shorter lactation than 28 days. Animal Reproduction Science $\mathbf{8 1}$ 287-293.

Gerritsen R, Soede NM, Hazeleger W, Langendijk P, Dieleman SJ, Taverne MAM \& Kemp B 2009 Intermittent suckling enables estrus and pregnancy during lactation in sows: Effects of stage of lactation and lactation during early pregnancy. Theriogenology 71 432-440.

Gerritsen R, Soede NM, Langendijk P, Dieleman SJ, Hazeleger W \& Kemp B 2008a Peri-oestrus hormone profiles and follicle growth in lactating sows with oestrus induced by intermittent suckling. Reproduction in Domestic Animals 43 1-8.

Gerritsen R, Soede NM, Langendijk P, Hazeleger W \& Kemp B 2008b The intermitted suckling regimen in pigs; consequences for reproductive performance of sows. Reproduction in Domestic Animals 43 29-35.

Knox RV \& Rodriguez Zas SL. 2001 Factors influencing estrus and ovulation in weaned sows as determined by transrectal ultrasound. Journal of Animal Science 79 2957-2963.

Koketsu Y \& Dial GD 1997a Factors associated with prolonged weaning-to-mating interval among sows on farms that wean pigs early Journal of the American Veterinary Association 211 894-898

Koketsu Y, Dial GD \& King VL 1997b Influence of various factors on farrowing rate on farms using early weaning. Journal of Animal Science 75 2580-2587.

Langendijk P, Berkeveld M, Gerritsen R, Soede NM \& Kemp B. 2006. Intermittent suckling: Tackling lactational anoestrus and alleviating weaning risks for piglets. In: J Wiseman, MA Varley, S McOrist and B Kemp (eds.) Paradigms in pig science. p 359-384. Nottingham University Press, Nottingham.

L.angendijk P, Dieleman SI, van Dooremalen C, Foxcroft GR, Gerritsen R, Hazeleger W, Soede NM \& Kemp B $2009 \mathrm{LH}$ and FSH secretion, follicle development and oestradiol in sows ovulating or failing to ovulate in an intermittent suckling regime. Reproduction, Fertility \& Development 21 1-10.

Le Cozier Y, Dagorn I, Dourmad JY, Johansen S \& Aumaître A 1997 Effect of weaning-to-conception interval and lactation length on subsequent litter size in sows. Livestock Production Science 51 1-11.

Lucy MC, Liu J, Boyd K \& Bracken C) 2001 Ovarian follicular growth in sows. Reproduction Supplement $5831-45$.

Mahan DC 1993 Effect of weight, split-weaning, and nursery feeding programs on performance responses of pigs to 105 kilograms body weight and subsequent effects on sow rebreeding interval. Journal of Animal Science 71 1991-1995.

Matte IJ, Pomar C \& Close WH 1992 The effect of interrupted suckling and splitweaning on reproductive performance of sows: A review. Livestock Production Science 30 195-212.

Prunier A, Soede N, Quesnel H \& Kemp B 2003 Productivity and longevity of weaned sows In: JR Pluske, I de Lividich and MWA Verstegen (eds.)
Weaning the pig. p 385-419. Wageningen Academic Publishers, Wageningen.

Quesnel H 2009 Nutritional and lactational effects on follicular development in the pig. In Control of Pig Reproduction VIII, pp 121-134. Eds H RodriguezMartinez, JL Vallet and AJ Ziecik, Nottingham University Press, Nottingham.

Quesnel H, Pasquier A, Mounier AM \& Prunier A 1998 Influence of feed restriction during lactation on gonadotropic hormones and ovarian development in primiparous sows. Journal of Animal Science 76 856-863.

Quesnel H \& Prunier A 1998 Effect of insulin administration before weaning on reproductive performance in feedrestricted primiparous sows. Animal Reproduction Science 51 119-129.

Rojanasthien S, Madej A, Lundeheim N \& Einarsson S 1987 Luteinizing hormone response to different doses of synthetic gonadotropin-releasing hormone during early and late lactation in primiparous sows. Animal Reproduction Science 13 299-307.

Sesti LA \& Britt JH 1993 Influence of stage of lactation, exogenous luteinizing hormone-releasing hormone, and suckling on estrus, positive feedback of luteinizing hormone, and ovulation in sows treated with estrogen. Journal of Animal Science 71 989-998.

Shaw HJ \& Foxcroft GR 1985 Relationships between L.H, FSH and prolactin secretion and reproductive activity in the weaned sow. Journal of Reproduction and Fertility 75 17-28.

Soede NM, Berkeveld $M$, Gerritsen R, Laurenssen B, Kuijken N, Langendijk P \& Kemp B 2009 Intermittent suckling regimes during a 4 or 5 week lactation period: Induction of lactational ovulation and effects on litter size. 8th international Conference on Pig Reproduction, Banff, Canada, 1-4 June 2009, Program \& Abstract Book, pp156, abstr 252-29.

Stevenson JS \& Davis DL 1984 Influence of reduced litter size and daily litter separation on fertility of sows at 2 to 5 weeks postpartum. Journal of Animal Science 59 284-293.

Svajgr A], Hays VW, Cromwell GL \& Dutt RH 1974 Effect of lactation duration on reproductive performance of sows. Journal of Animal Science 38 100-105.

Thaker MYC \& Bilkei G 2005 Lactation weight loss influences subsequent reproductive performance of sows. Animal Reproduction Science 88 309-318.

Tummaruk P, Lundeheim N, Einarsson S \& Dalin AM 2001 Reproductive performance of purebred hampshire sows in Sweden. Livestock Production Science 68 67-77.

Van Den Brand H, Dieleman SI, Soede NM \& Kemp B 2000 Dietary energy source at two feeding levels during lactation of primiparous sows: I. Effects on glucose, insulin, and luteinizing hormone and on follicle development, weaning-to-estrus interval, and ovulation rate. Journal of Animal Science 78 396-404.

Varley $M 1982$ The time of weaning and its effects on reproductive function. In: DJA Cole and GR Foxcroft (eds.) Control of pig reproduction. p 459-478. 
Butterworth, London.

Varley MA \& Foxcroft GR 1990 Endocrinology of the lactating and weaned sow. Journal of Reproduction and Fertility, Supplement 140 47-61.

Vesseur PC, Kemp B, den Hartog LA \& Noordhuizen JPTM 1997 Effect of split-weaning in first and second parity sows on sow and piglet performance. Livestock Production Science 49 277-285.

Willis HI, Zak LJ \& Foxcroft GR 2003 Duration of lactation, endocrine and metabolic state, and fertility of primiparous sows. Journal of Animal Science 81 2088-2102.

Xue JL, Dial GD, Marsh WE, Davies PR \& Momont HW 1993 Influence of lactation length on sow productivity. Livestock Production Science 34 253-265.

Zak L, Foxcroft GR \& Aherne FX 2008 Role of luteinizing hormone in primiparous sow responses to split weaning. Reproduction in Domestic Animals 43 445-450. 